\title{
Is bipolar disorder associated with premature aging?
}

\author{
O transtorno bipolar é associado a envelhecimento prematuro?
}

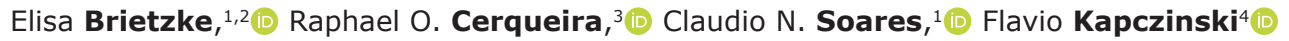

\begin{abstract}
Bipolar disorder (BD) is a chronic and recurrent mental illness, recognized by the presence of manic/ hypomanic and depressive episodes. It is associated with significant functional impairment in different domains, including work, finance, social activities, and autonomy. ${ }^{1}$ Replicated results on longitudinal observation data of the course of illness also suggest that, at least for a large proportion of patients, BD is also clinically progressive, and a higher number of episodes is associated with more pronounced cognitive deterioration, treatment resistance and functional decline. ${ }^{2}$

Neuroprogression is a concept recently introduced in the literature to designate the pathological rewiring of the brain in response to the toxicity associated with mood episodes. ${ }^{3} \mathrm{~A}$ large body of evidence supports the notion that patients with typical presentations of BD exhibit illness trajectories characterized by the presence of widespread structural brain abnormalities, including changes in cortical thickness ${ }^{4}$ and connectivity. ${ }^{5}$

While the progressive changes occurring in the brain of patients with $\mathrm{BD}$ are becoming better characterized, growing evidence also supports the notion that the pathophysiology of $\mathrm{BD}$ goes beyond the brain. It is wellknown that individuals with BD have high rates of general medical conditions, especially those related to obesity, glucose/insulin dysfunction and inflammation. ${ }^{6-10}$ These diseases are especially present in patients with a long time of illness and multi-episodic presentations,
\end{abstract}

suggesting that neuroprogression could be linked to a process of multisystemic progression in BD. ${ }^{11}$

The prototype of the multisystemic wear and tear process of the organism is aging. Interestingly, in the last decade, there has been a renewed interest in the study of different markers of premature aging in BD. ${ }^{12}$ For example, there is replicated evidence that individuals with BD have shorter telomeres compared to age- and sex-matched healthy controls. ${ }^{13,14}$ In addition, telomere shortening is more pronounced in individuals with BD in late stages than in those in early stages. ${ }^{15,16}$ Still, genes are not the only cellular structure that seems to be susceptible to premature aging in BD. Recently, Fries et al. ${ }^{17}$ demonstrated that it is possible to identify an acceleration of the epigenetic clock in individuals with BD compared to healthy controls. This epigenetic aging can be estimated by studying the methylation of different regions of DNA, which are known to change with age (DNA methylation age), and by the mitochondrial DNA copy number. In that study, older patients with $\mathrm{BD}$ presented premature epigenetic aging compared to healthy controls, suggesting that epigenetic changes could be mechanistically linked to psychopathology in BD. ${ }^{17}$

Another biological dimension of aging that seems to be altered in $B D$ is the immune system aging. Several reports are available on the association between manic and depressive episodes and proinflammatory states, ${ }^{18,19}$

\footnotetext{
1 Department of Psychiatry, Queen's University, Kingston, ON, Canada. 2 Centre for Neuroscience Studies, Queen's University, Kingston, ON, Canada. 3 Departamento de Psiquiatria, Universidade Federal de São Paulo, São Paulo, SP, Brazil. ${ }^{4}$ Department of Psychiatry and Behavioral Neurosciences, McMaster University, Hamilton, ON, Canada.

Submitted May 15 2019, accepted for publication Jun 272019.

Suggested citation: Brietzke E, Cerqueira RO, Soares CN, Kapczinski F. Is bipolar disorder associated with premature aging? Trends Psychiatry Psychother. 2019;41(4):315-317. http://dx.doi.org/10.1590/2237-6089-2019-0038
} 
as well as evidence that multiple episodes are able to reprogram the immune system towards a longstanding proinflammatory status. ${ }^{20}$ Moreover, recent findings suggest that aging-related immune abnormalities in BD go beyond increased levels of proinflammatory cytokines and include dysfunction in different lymphocyte subpopulations such as T-suppressor cells and increased proportions of senescent T cells. ${ }^{21,22}$

Molecular correlates of aging in mood disorders also include reduced levels of brain-derived neurotrophic factor (BDNF) and oxidative stress imbalances, ${ }^{23,24}$ which are also critical mediators of neuroprogression. ${ }^{25-27}$ These phenomena have been consistently associated with critical neuropsychiatric domains in $B D$, such as cognitive impairment. ${ }^{28,29}$ BDNF levels in BD decline with age, ${ }^{30}$ suggesting that this mediator could be implicated in neural accelerated aging in this condition.

The treatment of BD may have a putative effect, reversing and/or retarding imbalances in the pathways related to accelerated aging on the one hand, and activating neurotrophic pathways on the other. BDNF levels, for example, have been well-documented to increase following treatment of acute mania31,32 although BDNF levels may not return to normal levels in chronic scenarios despite clinical improvement with a therapeutic intervention, indicating progression of the disease. ${ }^{31}$ In the last two decades, lithium - one of the main therapeutic agents for BD - has shown to have impacts on multisystemic pathways. For example, proinflammatory states seen in mood episodes seem to be reduced and normalized after lithium therapy. ${ }^{33}$ Recent studies also suggest that lithium has a positive effect on leukocyte telomere length. ${ }^{34,35}$ Some studies have reported decreased oxidative stress parameters in plasma levels in early stages in previously unmedicated individuals with $\mathrm{BD}$ after 6 weeks, ${ }^{36}$ and also in individuals with $\mathrm{BD}$ during euthymia. ${ }^{37} \mathrm{~A}$ neuroprotective effect of lithium could be associated with its potential to increase antioxidant agents and counterbalance the neurotoxicity associated with neuroprogression.

In conclusion, there are emerging data suggesting that BD follows a progressive trajectory in patients with typical presentations, especially when not properly treated. ${ }^{2}$ A large part of central and peripheral changes in $\mathrm{BD}$ related to both neuroprogression and multisystemic progression could be understood using the concept of premature aging. The conception of BD as a disease of accelerated aging opens new insights for research into its pathophysiology, prevention and treatment, and reinforces the need for early recognition and intervention. In addition, it opens the possibility of exploring pharmacological and non-pharmacological anti-aging interventions in BD.

\section{Acknowledgements}

Elisa Brietzke has received a research Establishment Grant from Queen's University Faculty of Health Sciences. Flavio Kapczinski has received grants from the Stanley Medical Research Institute (grant 07TGF/1148), Instituto Nacional de Ciência e Tecnologia - Conselho Nacional de Desenvolvimento Científico e Tecnológico National (INCT-CNPq; grant 465458/20149), and the Canada Foundation for Innovation (CFI). Claudio N. Soares has received grants from the Ontario Brain Institute, the Academic Health Science Centre Alternative Funding Plan (AHSC AFP) Innovation Fund, and the Ontario Research Fund-Research Excellence.

\section{Disclosure}

Elisa Brietzke has received personal fees from Daiichi Sankyo and Otsuka. Flavio Kapczinski has received personal fees from Daiichi Sankyo and Janssen-Cilag. Claudio N. Soares has received personal fees from Otsuka and Lundbeck. No other conflicts of interest declared concerning the publication of this article.

\section{References}

1. Rosa AR, Sánchez-Moreno J, Martínez-Aran A, Salamero M, Torrent $C$, Reinares $M$, et al. Validity and reliability of the Functioning Assessment Short Test (FAST) in bipolar disorder. Clin Pract Epidemiol Ment Health. 2007;3:5.

2. Kessing LV, Andersen PK. Evidence for clinical progression of unipolar and bipolar disorders. Acta Psychiatr Scand. 2017; 135:51-64.

3. Passos IC, Mwangi B, Vieta E, Berk M, Kapczinski F. Areas of controversy in neuroprogression in bipolar disorder. Acta Psychiatr Scand. 2016:134:91-103.

4. Suh JS, Schneider MA, Minuzzi L, MacQueen GM, Strother $\mathrm{SC}$, Kennedy $\mathrm{SH}$, et al. Cortical thickness in major depressive disorder: a systematic review and meta-analysis. Prog Neuropsychopharmacol Biol Psychiatry. 2019;88:287-302.

5. Syan SK, Smith M, Frey BN, Remtulla R, Kapczinski F, Hall GBC, et al. Resting-state functional connectivity in individuals with bipolar disorder during clinical remission: a systematic review. J Psychiatry Neurosci. 2018;43:298-316.

6. Mansur RB, Santos CM, Rizzo LB, Asevedo E, Cunha GR, Noto $M N$, et al. Brain-derived neurotrophic factor, impaired glucose metabolism, and bipolar disorder course. Bipolar Disord. 2016;18:373-8.

7. Mansur RB, Rizzo LB, Santos CM, Asevedo E, Cunha GR, Noto $M N$, et al. Impaired glucose metabolism moderates the course of illness in bipolar disorder. J Affect Disord. 2016;195:57-62.

8. SayuriYamagata A, Brietzke E, Rosenblat JD, Kakar R, McIntyre RS. Medical comorbidity in bipolar disorder: the link with metabolic-inflammatory systems. ] Affect Disord. 2017;211:99106.

9. McIntyre RS, Alsuwaidan M, Goldstein BI, Taylor VH, Schaffer A, Beaulieu S, et al. The Canadian Network for Mood and Anxiety Treatments (CANMAT) Task Force recommendations for the management of patients with mood disorders and comorbid metabolic disorders. Ann Clin Psychiatry. 2012;24:69-81.

10. Brietzke E, Stabellini R, Grassi-Oliveira R, Lafer B. Cytokines in bipolar disorder: recent findings, deleterious effects but promise for future therapeutics. CNS Spectr. 2011;16:157-68. 
11. Brietzke E, Mansur RB, McIntyre RS. Coronary calcium score as an expression of multisystemic progression of bipolar disorder. Braz J Psychiatry. 2018;40:459-60.

12. Rizzo LB, Costa LG, Mansur RB, Swardfager W, Belangero SI, Grassi-Oliveira R, et al. The theory of bipolar disorder as an illness of accelerated aging: implications for clinical care and research. Neurosci Biobehav Rev. 2014;42:157-69.

13. Darrow SM, Verhoeven JE, Révész D, Lindqvist D, Penninx BW, Delucchi $\mathrm{KL}$, et al. The association between psychiatric disorders and telomere length: a meta-analysis involving 14,827 persons. Psychosom Med. 2016;78:776-87.

14. Powell TR, Dima D, Frangou S, Breen G. Telomere length and bipolar disorder. Neuropsychopharmacology. 2018;43:445-453.

15. Huang YC, Wang LJ, Tseng PT, Hung CF, Lin PY. Leukocyte telomere length in patients with bipolar disorder: an updated meta-analysis and subgroup analysis by mood status. Psychiatry Res. 2018;270:41-9.

16. Barbé-Tuana FM, Parisi MM, Panizzutti BS, Fries GR, Grun LK, Guma FT, et al. Shortened telomere length in bipolar disorder: a comparison of the early and late stages of disease. Braz J Psychiatry. 2016;38:281-6.

17. Fries GR, Bauer IE, Scaini G, Wu MJ, Kazimi IF, Valvassori SS, et al. Accelerated epigenetic aging and mitochondrial DNA copy number in bipolar disorder. Transl Psychiatry. 2017;7:1283.

18. Rosenblat JD, Brietzke E, Mansur RB, Maruschak NA, LeeY, McIntyre RS. Inflammation as a neurobiological substrate of cognitive impairment in bipolar disorder: evidence, pathophysiology and treatment implications. J Affect Disord. 2015;188:149-59.

19. Modabbernia A, Taslimi S, Brietzke E, Ashrafi M. Cytokine alterations in bipolar disorder: a meta-analysis of 30 studies. Biol Psychiatry. 2013;74:15-25.

20. Ferrari P, Parisi MM, Colombo R, Becker M, Fries G, Ascoli BM, et al. Depression and mania induce pro-inflammatory activation of macrophages following application of serum from individuals with bipolar disorder. Clin Psychopharmacol Neurosci. 2018;16:1038.

21. Rizzo LB, Swardfager $W$, Maurya $P K$, Graiff $M Z$, Pedrini $M$, Asevedo $E$, et al. An immunological age index in bipolar disorder: a confirmatory factor analysis of putative immunosenescence markers and associations with clinical characteristics. Int J Methods Psychiatr Res. 2018;27:e1614.

22. Yamagata AS, Rizzo LB, Cerqueira RO, Scott J, Cordeiro Q, McIntyre RS, et al. Differential impact of obesity on CD69 expression in individuals with bipolar disorder and healthy controls. Mol Neuropsychiatry. 2018;3:192-6.

23. Maurya PK, Noto C, Rizzo LB, Rios AC, Nunes SO, Barbosa DS, et al. The role of oxidative and nitrosative stress in accelerated aging and major depressive disorder. Prog Neuropsychopharmacol Biol Psychiatry. 2016;65:134-44.

24. Kapczinski F, Dias VV, Kauer-Sant'Anna M, Brietzke E, Vázquez GH Vieta $E$, et al. The potential use of biomarkers as an adjunctive tool for staging bipolar disorder. Prog Neuropsychopharmacol Biol Psychiatry. 2009;33:1366-71.

25. Gama CS, Kunz M, Magalhães PV, Kapczinski F. Staging and neuroprogression in bipolar disorder: a systematic review of the literature. Braz J Psychiatry. 2013;35:70-4.
26. Fries GR, Pfaffenseller $B$, Stertz $L$, Paz AV, Dargél AA, Kunz M, et al. Staging and neuroprogression in bipolar disorder. Curr Psychiatry Rep. 2012;14:667-75.

27. Berk M, Kapczinski F, Andreazza AC, Dean OM, Giorlando F, Maes $M$, et al. Pathways underlying neuroprogression in bipolar disorder: focus on inflammation, oxidative stress and neurotrophic factors. Neurosci Biobehav Rev. 2011;35:804-17.

28. Dias VV, Brissos S, Frey BN, Andreazza AC, Cardoso C, Kapczinski F. Cognitive function and serum levels of brain-derived neurotrophic factor in patients with bipolar disorder. Bipolar Disord. 2009; 11:663-71.

29. Kapczinski F, Frey BN, Kauer-Sant'Anna M, Grassi-Oliveira R. Brain-derived neurotrophic factor and neuroplasticity in bipolar disorder. Expert Rev Neurother. 2008;8:1101-13.

30. Yatham LN, Kapczinski F, Andreazza AC, Trevor Young L, Lam RW, Kauer-Sant'anna M. Accelerated age-related decrease in brain-derived neurotrophic factor levels in bipolar disorder. Int J Neuropsychopharmacol. 2009;12:137-9.

31. Nuernberg GL, Aguiar B, Bristot G, Fleck MP, Rocha NS. Brainderived neurotrophic factor increase during treatment in severe mental illness inpatients. Transl Psychiatry. 2016;6:e985.

32. Fernandes BS, Gama CS, Ceresér KM, Yatham LN, Fries GR, Colpo $G$, et al. Brain-derived neurotrophic factor as a state-marker of mood episodes in bipolar disorders: a systematic review and meta-regression analysis. J Psychiatr Res. 2011;45:995-1004.

33. van den Ameele S, van Diermen L, Staels W, Coppens V, Dumont $\mathrm{G}$, Sabbe $B$, et al. The effect of mood-stabilizing drugs on cytokine levels in bipolar disorder: a systematic review. J Affect Disord. 2016;203:364-73.

34. Martinsson $L$, Wei $Y, X u$ D, Melas PA, Mathé AA, Schalling $M$, et al. Long-term lithium treatment in bipolar disorder is associated with longer leukocyte telomeres. Transl Psychiatry. 2013;3:e261.

35. Squassina A, Pisanu C, Congiu D, Caria P, Frau D, Niola $P$, et al. Leukocyte telomere length positively correlates with duration of lithium treatment in bipolar disorder patients. Eur Neuropsychopharmacol. 2016;26:1241-7.

36. de Sousa RT, Zarate CA Jr, Zanetti MV, Costa AC, Talib LL, Gattaz $W F$, et al. Oxidative stress in early stage Bipolar Disorder and the association with response to lithium. J Psychiatr Res. 2014;50:3641

37. Bengesser SA, Lackner N, Birner A, Platzer M, Fellendorf FT, Queissner R, et al. Mood stabilizers, oxidative stress and antioxidative defense in euthymia of bipolar disorder. CNS Neurol Disord Drug Targets. 2016;15:381-9.

\section{Correspondence:}

Elisa Brietzke

Department of Psychiatry, Queen's University

752 King St $W$

ON K7L 4X3 - Kingston - Canada

Tel.: +1-613-5444900, Fax: +1-613-5485580

E-mail: elisabrietzke@hotmail.com 